Proceedings of the 34th

Conference on Decision \& Control

New Orleans, LA - December 1995

\title{
Rotating stall and surge control: A survey
}

TA10 10:00

\author{
Bram de Jager \\ Faculty of Mechanical Engineering, WH 2.137 \\ Eindhoven University of Technology \\ P.O. Box 513, 5600 MB Eindhoven, The Netherlands \\ Email: A.G.de.Jager@wfw.wtb.tue.nl Fax: +31 402447355.
}

The Abstract

The paper presents an analysis of the current state of the art in the control of aero- or hydrodynamic instabilities in turbomachines. It describes the flow phenomena associated with rotating stall and surge, discusses methods devised to prevent these instabilities to occur, but concentrates mainly on the active control (stabilization) of the unstable flows. It appears that lately significant progress has been made in this area. It seems to foster to a more mature state, although several problems deserve further consideration. The consequences of this state of the art for several interested parties, researchers, developers, manufacturers, and users, are stipulated.

\section{The Motivation}

There are two main types of continuous flow compressors: the axial compressor, where the flow leaves the compressor in the direction parallel to the rotational axis, and the centrifugal compressor, where the flow leaves the compressor in the direction perpendicular to the rotational axis. Rotating stall, surge, and other flow instabilities occur in turbomachinery, in particular in axial and radial compressors, and limit its efficiency and effectiveness, and by that its usefulness. Preventing these instabilities to occur would benefit the large community of users of turbomachines where these phenomena are important in employing this equipment.

\section{The Phenomena}

Rotating stall is an instability phenomenon, local to the compressor, in which a circumferentially uniform flow pattern is disturbed. A local region or local regions appear where the flow is stagnant: the flow stalls. The regions propagate in the same direction as the blades (i.e., regions of stall rotate around the annular flow path), at a fraction of the rotor speed. This speed is often between one fifth and half of the wheel speed, at least for fully developed stall, initial rotating stall cells move faster [9]. The part of the area of the annular flow path the stalled regions occupy may also grow exponentially with time, until a certain size is reached. This depends on the slope of the pressure/flow characteristic for constant speed in the compressor performance map, in the sequel called compressor characteristic or speed lines, and compressor map, respectively, see Fig. 1.

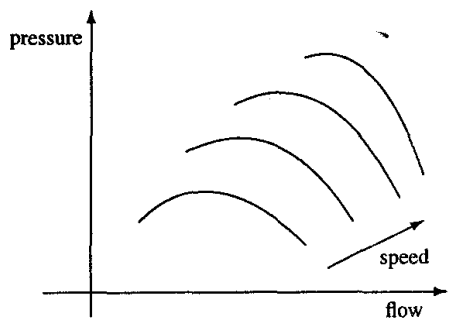

Figure 1: Compressor map with speed lines

Rotating stall may occur in some parts of the machine only, e.g., in some stages. Rotating stall is regarded, at least for axial machines [19], as an inception of a more severe and potentially dangerous flow stability problem, namely surge. Surge is a self-excited cyclic phenomenon, affecting the compression system as a whole, characterized by large amplitude pressure rise and annulus av eraged mass flow fluctuations. Even flow reversal is possible. This type of behavior is a large amplitude limit cycle oscillation. It starts to occur in a region of the compressor map where the pressure rise/mass flow characteristics for constant speed have a positive slope that exceeds a certain value determined by characteristics of the compressor and the slope of the load line [19]. Essentially, the slope of the instantaneous mass flow/pressure rise characteristic is important. As a consequence, the onset of surge not only depends on the compressor characteristics, but also on the flow/pressure characteristic of the system that it discharges into. In [39] results are reported related to the question why the compressor map has a region with positively sloped speed lines.

\section{0-7803-2685-7/95 \$4.00 @ 1995 IEEE}

The essential differences between rotating stall and surge are that the average flow in pure rotating stall is steady in time, but the flow has a circumferentially nonuniform mass deficit, while in pure surge the flow is unsteady but circumferentially uniform. Because it is steady, rotating stall may be local to the compressor or to parts of the compressor. Due to its unsteadiness, surge involves the entire compression system. So, the phenomena can be regarded as distinct. On the other hand, both phenomena are natural oscillatory modes of the compression system, with surge corresponding to the lowest (zero) order mode, and thus they are related $[30,36]$.

Discussions are still ongoing if rotating stall is important for centrifugal compressors, and perhaps also single stage axial compressors, or if only surge is important for these machines. Contradictory opinions and experimental results could be quoted, suggesting that more, hitherto unrecognized, factors are important. In centrifugal compressors, rotating stall often has little effect on pressure rise, and therefore on surge.

For multistage axial compressors, rotating stall seems more important at low shaft speeds, while surge occurs more frequently at high speeds [11, 22]. This is related to the ratio of pressure forces and flow momentum which increases with increasing wheel speed. Also, rotating stall is often more difficult to recover from than surge [7]. Recovery can be thought to follow the reverse path: a region of "clean" flow develops that grows till it occupies the total annulus.

There are several types of rotating stall [9].

- Part-span and full-span, where only a restricted region of the blade passage (most often the tip) or the complete height of the annulus is stalled.

- Small (large) scale, where a small (large) part of the annular flow path is blocked.

For a typical rotating stall pattern, displayed in the compressor map, see Fig. 2. Starting from the unstalled characteristic, rotating stall occurs at (1). The operating point then proceeds, indicated by the straight line, to the so-called stalled characteristic at (2). If operating point (2) is stable, the compressor will remain there, until measures are taken to bring it back to the unstalled characteristic.

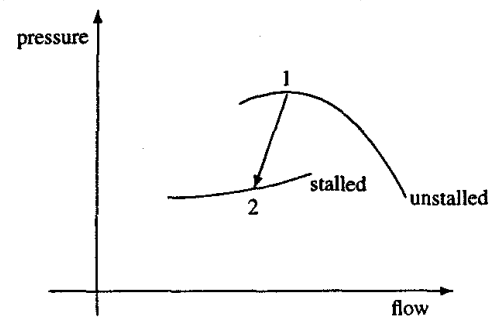

Figure 2: Compressor map with stalled flow characteristic

Surge has a more complex typology than rotating stall. At least four different categories of surge, with respect to flow and pressure fluctuations, can be distinguished $[19,26,11]$

- Mild surge, a phenomenon with small pressure fluctuations and a periodicity governed by the Helmholtz resonance frequency. Flow reversal does not occur

- Classic surge, with larger oscillations and at a lower frequency than mild surge (although high frequency oscillations may be present also: the dynamics is nonlinear and introduces higher harmonics), but no flow the dyna

- Modified surge, where the entire annulus flow fluctuates in axial direction but rotating stall is superimposed, so the flow is unsteady and nonaxisymmetric. It is a mix of rotating stall and classic surge phenomena.

- Deep surge, a more severe version of classic surge, where even flow reversal is possible. This is an unsteady but axisymmetric limit cycle for the flow.

The terminology is not unique, e.g., in [17] the term classic surge is used for phenomena that are termed here modified surge. Figure 3 gives an example of a deep surge cycle depicted in the compressor map. The cycle starts at 
(1) where the flow becomes unstable. It then goes very fast (approximately represented by the straight line) to the negative flow characteristic at (2) and descends this until the flow is approximately zero (3). Then it proceeds very fast to the normal characteristic at (4) where it starts to climb to point (1). Arriving at point (1) the cycle repeats, unless measures are taken to avoid that.

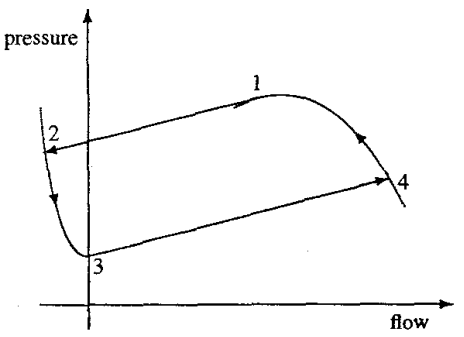

Figure 3: Compressor map with deep surge cycle

For both radial and axial turbomachines one or some of these categories may occur in sequence. Assume that the plenum pressure at the exit of the compressor is increased, with constant wheel speed. First mild surge can occur, Fllowed by rotating stall or modified surge, and then possibly by one of classic or deep surge [11]. Rotating stall can subsequently lead to surge (by growth of the stalled area till it occupies the total annular circumference), or the system may artive at a new stable operating point on the stalled characteristic, with severely reduced performance and efficiency. Deep surge itself may be unstable to nonaxisymmetric disturbances and develop into modified surge [17]. Which sequence of phenomena will be followed depends on the characteristics of the compression system, especially on the instantaneous mass How/pressure rise characteristic.

For centrifugal compressors the situation is even more involved, because one or both of the two main components (impeller and diffuser) may stall individually or simultaneously. Also, a distinction can be made between intermittent and persistent stall. Surge can only occur if both the components stall simultaneously, which is obvious from the phenomenological definition of surge. If one component stalls, it can be stabilized by the other [34]. One could imagine the same to hold for multistage axial machines, where only some stages stall ln this sense this is never mentioned in the reviewed literature. It is only mentioned as an intermediate stage to fully developed rotating stall encompassing all stages.

The transfer of mild surge to other types of surge or rotating stall is characterized by increasing amplitudes of the pressure and flow fluctuations. So, the nonlinear limit cycle oscillations characterizing surge will start as small (linear) amplitude oscillations. Those small fluctuations may be used to detect the onset of a rotating stall/surge phenomenon. For a centrifugal compressor [39] found that the onset of surge was related to the leakage flow through the tongue gap (the part of the volute near the diffuser) under off-design conditions.

According to [11], in axial compressors surge can be regarded as the logical consequence of effects triggered by the onset of rotating stall, while precursors of rotating stall are spatially coherent pressure waves [27]. Others call them modal perturbations of the circumferentially uniform flow field. Progressive growth of these perturbations leads to rotating stall. For high speed multistage axial machines it is argued $[6,27]$ that rotating stall is not the result of growing amplitude of initially small amplitude waves, but of a blast wave emanating from the back of the machine, a sudden change triggered by a disturbance. To add to the confusion, [9] states that often not growing modal perturbations, but short rotating stall cells, emanating from the front of the machine, trigger the path to fully developed rotating stall cells. For a mixed-flow pump [20] reports an inception of rotating stall by flow separation at a corner of the impeller triggering the onset of inlet flow recirculation leading to rotating stall. It appears that several mechanisms for rotating stall inception play a role. We indicated four of them, there may be more. Apparently, all factors influencing the onset of rotating stall are not yet identified.

Rotating stall and surge phenomena restrict the performance (pressure rise) and efficiency (specific power consumption) of the compressor. This may lead to rapid heating of the blades and to an increase in the exit temperature of the compressor. Moreover, the unsteady fluid-dynamic excitation results in additional periodic loads on the blades, causing blade vibrations and fatigue (and so reduces durability) and may even cause severe damage to the machine due to unacceptable levels of system vibration $[26,33]$. All the surge phenomena, except mild surge that is normally deemed acceptable, are potentially hazardous conditions, which is due to the mechanical and thermal loads, and should be avoided in normal operation. A distinction can be made, however, between high speed axial machines, where surge can be damaging, and low speed axial machines, where surge is characterized by a more gentle pulsing of the whole flow [6]

Rotating stall, if it occurs in isolated parts of the machine, may cause acoustic resonances and stall flutter [6]. Furthermore, the rotating stall may be unrecoverable, e.g., changing the wheel speed (for instance by changing the fuel feed to a combustor) will not restore the system to the unstalled condition. In case of so-called "hung" stall, this is caused by a coupled compressor/combustor instability. To recover from rotating stall then requires a full stop and restart of the machine.

The phenomena described above are related to basic fluid dynamic properties or principles. An exposition of these relations is outside the scope of this paper.

At least three variables are involved in demarcating the so-called surge/rotating stall line, a barrier that separates regions of stable and unstable operation in the compressor map.

- Compressor speed $n$, e.g., nondimensional wheel speed or tip speed expressed in Mach number.

- Mass flow $\phi$, e.g., nondimensional flow coefficient $\left(C_{x} / U\right.$ with $C_{x}$ the axial flow velocity and $U$ the mean blade speed) or mass flow divided by the choked mass flow.

- Pressure rise $\Psi$, e.g., the nondimensional pressure coefficient $\left(\Delta p / \rho U^{2}\right.$, with $\Delta p$ the total to static pressure rise and $\rho$ the specific mass) or the pressure ratio between exit and inlet of the compressor.

In general four nondimensional variables are needed to define the compressor characteristics. Additionally the temperature rise, or a related variable like the efficiency, could be added, but usually this is not needed to characterize the surge line in the compressor map. The three variables $\Psi, \phi$, and $n$ are (at least in steady state) connected according to relations expressed in the compresso map, so only two variables are really independent. Figure 4 gives a tentative example of a compressor map with the surge line. Remark that the pairs $(\Psi, \phi)$ and $(\phi, n)$ uniquely determine the operating point, which is not necessarily the case for the pair $(\Psi, n)$ due to the nonlinearity of the characteristics.

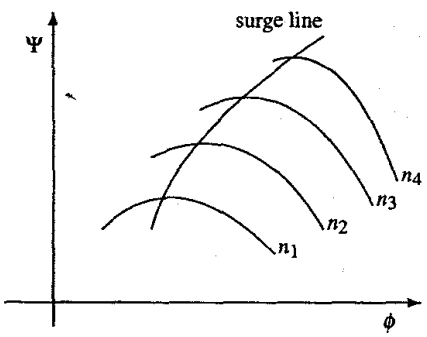

Figure 4: Compressor map with surge line

3. The Measures

Several measures are presently used to cope with surge [5]. They can be classified as follows.

1. Surge control, surge avoidance, or surge protection, where the machine is prevented to operate in a region near and beyond the surge line. This can be regarded as an open loop strategy.

2. Surge detection and control or surge detection and avoidance, where the surge avoidance system starts acting if (the onset of) surge is detected. This can be regarded as a closed loop strategy.

3. Surge suppression or (active) surge control, first mentioned in the open literature in [13], where the flow instabilities are stabilized by one or more effectors acting on appropriate signals from a controller that receives relevant information from well chosen sensors.

Remark that the first alternative in the terminology is used in [5], while the second (bold) alternative is more appropriate from the viewpoint of control theory [10] and will be used in the sequel. Also note that the word "surge" used in the above, and in the remainder of this section, can be regarded as synonymous with "rotating stall and surge."

Measures to avoid surge in turbomachinery are abundant [5]. Because the operating point is established by $(\Psi, \phi, n)$, all measures aim at influencing a least one of these factors. Some measures aim at increasing the flow rate $\phi$ by discharging into a by-pass, by feeding back excess flow through a recirculation loop, or by blowing of excess flow with a vent (bleeding). This may be done after the compressor, or between compressor stages. Other measures aim at reducing or increasing the speed $n$, e.g., by modifying the torque on the compressor by changing the fuel consumption of a driving turbine or by changing the voltage to a motor. Variable wheel speed (e.g., because of a constant supplied torque and varying demanded torque) also has a stabilizing effect [19]. The last possibility is to influence the pressure rise $\Psi$. This can be achieved by manipulating valves in the flow. Because the three characteristic variables are connected according to relations shown in the compressor map, influencing one of them implicitly influences the others. The measures can also be divided in those changing the compressor characteristic and those changing the operating line, effectively lowering it [33]. Both lead to operating points further away from the unstable region.

The main differences in the published surge avoidance methods arise in the area of detection of the flow conditions (pressure rise and flow rate) and in 
the instrumentation used to do that. In general, one strives after simple, non intrusive, low cost, and reliable instrumentation.

Characterizing surge, or detecting the onset of surge, is necessary for a surge detection and avoidance system. To reliably detect surge, the gross (and perhaps even detailed) features of it should be known. Surge phenomena in axial compressors are well understood. Those in centrifugal compressors, like those typically used in turbochargers, are less well understood [19]. Another problem, besides the detection of surge, is how to act quickly enough, after the detection of surge, in order to prevent the machine entering into deep surge. Allowable reaction times are very short.

The accuracy of the detection of surge or rotating stall depends on the instrumentation, that should measure quantities strongly related to surge phenomena, or, better, to phenomena that eventually could lead to surge. Due to the small time scales involved, the sensors and actuators should have small time constants and delays. Furthermore, the instrumentation should preferably not be intrusive, or, if it is, not be placed upflow but downflow from the compressor. Also, the instrumentation should be as limited as possible to restrict investment and maintenance costs, to simplify repair, and to ensure the reliability of the machine. For a specific system, a jet engine, measuring the Mach number at the exit of the turbomachine proved to be a reliable way of detecting surge [8]. It is not known if this measure is also suitable for other types of turbomachines, e.g., a turbocharger. A fault detection approach to identify rotating stall and surge is taken in [37].

The research area of active control of surge is upcoming and active. The detailed treatment of active control is delayed to after the discussion of the problems related with the surge (detection and) avoidance measures. In this section, to start with, we give only some general remarks. Flow stabilization is a difficult problem. Until now, the ideas proposed are often intimately connected with a specific machine, and no general methodology is available. With some exceptions, instabilities cannot be prevented completely, but the region of stable operation may be enhanced significantly. See Fig. 5 for an example of a potential improvement by active control.

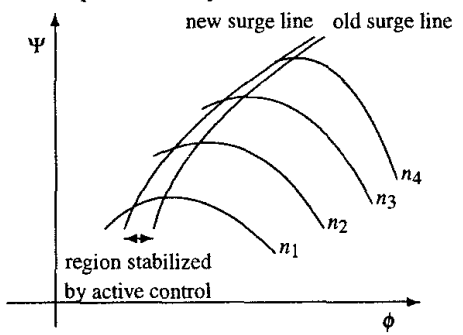

Figure 5: Compressor map with effect of active control

\section{The Problems}

Conventionally, due to the uncertainties in detection of flow conditions or surge, the transients in flow rate, the ingestion of nonaxisymmetric or otherwise disturbing flows, the high frequencies of the pressure fluctuations, the delays in reacting to the onset of surge, and the time constants of sensors and actuators, one must allow for a safety margin (the rotating stall or surge margin) in a surge avoidance scheme [5]. A surge avoidance line (also called surge control line) in the compressor map is therefore introduced - some distance, e. $10 \%$ of flow rate, from the actual surge line, although this margin can be altered dynamically - which the compressor state is not allowed to cross, see Fig. 6

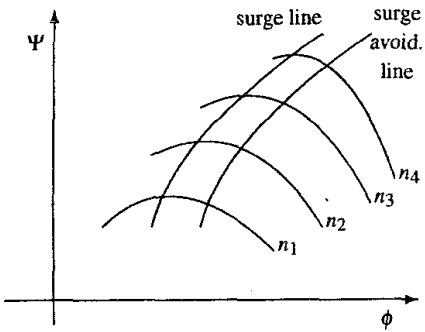

Figure 6: Compressor map with surge avoidance line

The margin does not follow from a detailed analysis of the influence of disturbances and uncertainties on the surge behavior, but is fixed by empirical rules on an ad-hoc basis. The aim of the margin is to achieve that the turbomachine never - under no circumstances, despite all uncertainties - goes into surge. On the other hand, this restriction of the feasible operating region unduly restricts the capabilities of the machine. At least five aspects are important here, see also [26].
- Surge avoidance measures, e.g., recycle or bleed, have significant effects on energy consumption and should preferably be avoided. Figure 7 gives an example of the waste with bleed. Two bleed flows are indicated. One

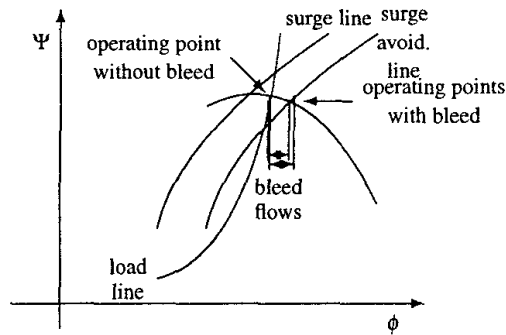

Figure 7: Compressor map with effect of bleed

for constant speed and one for constant pressure rise. It is assumed that the new operating point is exactly on the surge avoidance line. Often it is well inside the feasible region, so the indicated bleed flows are only lower limits for the ones encountered in practice. The bleed flows are compressed, consuming energy, but are not useful for the process and reduce the overall efficiency of the compression system. Examples are available where a compression system was so poorly designed that continuous recycle or bleed was necessary for proper operation.

- The point of peak pressure rise for constant speed, representative of a peak in compressor performance, is often near the surge line and cannot be reached if a safety margin is introduced, see Fig. 6 . This limits the effectiveness of the compression system.

- In the compressor map the region of lowest specific power consumption or highest efficiency, $\eta_{\max }$, is close to, or maybe even encompasses, the surge line (or could be there for a design that emphasizes efficiency instead of stability). For an indication, not necessarily realistic, see Fig. 8. Introducing a safety margin moves the feasible operating region of the machine away from the region of lowest specific power consumption, decreasing efficiency and increasing the operational costs.

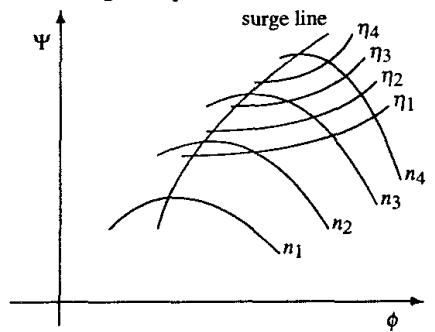

Figure 8: Compressor map with efficiency $(\eta)$ contours

- Normally the load line is not fixed because of processes that are shut down, or temporal, e.g. diurnal, changes in the rate of production, etc. During transients caused by a shift in the load line, which is presumably the most common cause for a change in compressor working point besides start-up and shut-down, the compressor control has to realize several, possibly conflicting, goals. Assume that one of the goals is a constant supply pressure at the exit of the compressor. If the demanded load is increased, the flow may approach the stone wall line (choked flow in parts of the machine). This could be avoided by lowering the supply pressure. If this is not possible, like with our stated goal, a larger compressor has to be purchased to fulfill the specifications, increasing the investment costs. Decreasing the demand on the compression system may cause the working point to enter the safety region. Then the goals of constant pressure and surge avoidance are conflicting. A lower supply pressure could prevent the system to enter the safety region, but this conflicts with the stated goal of constant supply pressure. This conflict could be avoided by using a compressor with slightly smaller capacity, preventing the system to cross the surge avoidance line. If the shifts in load are substantial, a single compressor may be unable to satisfy the specifications. A safety margin therefore limits the range of feasible operation of the machine, and, if making it smaller than the required range, may cause the use of a larger number of compressors. Figure 9 represents a situation where the required range is larger than the feasible one. This can only be remedied by using two compressors (perhaps of different capacity) or by a substantial shift of the surge avoidance line in the direction of lower mass flows, assuming the maximum flow is not hampered by that.

- During transients with fixed load, requiring the system to go to another point on the same load line or during start-up and shut-down, the machine does not follow the quasi-static load line in the compressor map. Dynamic effects may cause it to move closer to the surge line. Here, 


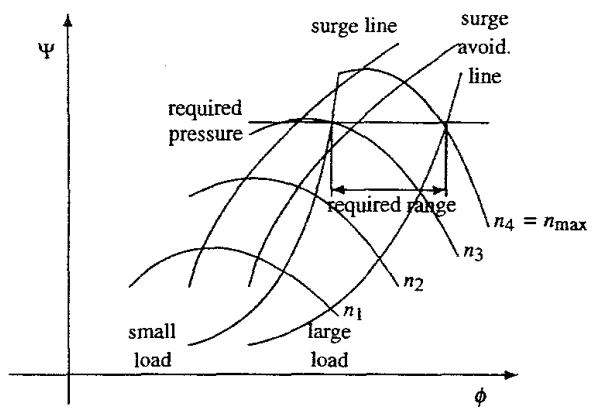

Figure 9: Required ranges for load variations

we encounter at least two cases. The first for closely coupled compressor/combustor/turbine triples, as in aeroengines. During acceleration, in this case, the exit pressure of the compressor may rise because of the backpressure of the turbine and pressure drop over the combustor that increase with increased fuel consumption, while the increase in compressor speed and air flow has not yet taken off. During deceleration the effect is just the reverse. See Fig. 10 for this behavior.

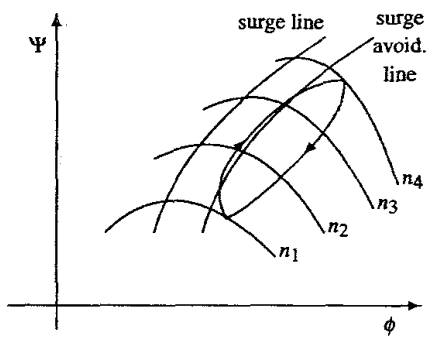

Figure 10: Transients in aeroengines

The other case occurs when the volume of the system in which the compressor discharges, the plenum, is quite large. Now the instantaneous incremental pressure rise is very small while the airflow increases substantially during acceleration or drops during deceleration. See Fig. 11 for this behavior.

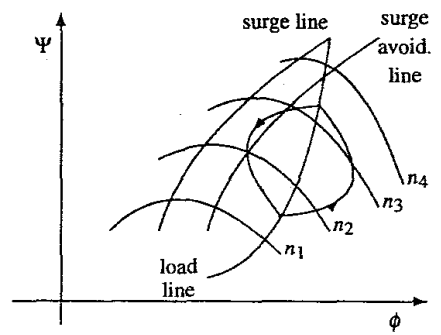

Figure 11: Transients in systems with large plenum

In both cases the operating point moves closer to the surge line, during one of accelerating or decelerating transients. When the machine crosses the surge avoidance line, and enters the safety region, the acceleration or deceleration is limited by surge avoidance measures. Therefore, a safety margin effectively limits the achievable transient performance of the machine. For compressor/combustor/turbine setups, an additional consideration during acceleration is the turbine temperature that may limit the slope of the fuel increase: more fuel but not yet more flow will increase the combustor exit temperature

Enlarging the region of feasible operating points has the following advantages. First, it means that the machine may operate closer to the region of high pressure rise or low specific power consumption, increasing efficiency and reducing costs. Second, the conflicting goals of constant supply pressure and surge avoidance and stone wall line avoidance may be assimilated, perhaps also with a lower number of compressors and so with reduced investment costs. Finally, larger transients are possible, so the machine may react quicker to changing operating condition requirements, increasing effectiveness.
5. The Solutions

Enlarging the feasible region, by preventing or suppressing rotating stall or surge, is possible in several ways:

1. Better matching of compressor and discharge system specifications. This will move us closer to the area of peak performance, but it will still not be reached.

2. Reduction of the safety margin (so shift the surge avoidance line closer to the surge line). This is possible by improved flow condition or surge detection, by reduced uncertainty in the location of the surge line in the compressor map, by reduced disturbances in the inlet/outlet flow fields and pressure, by a more appropriate (faster) action of the surge avoidance system [23], etc. The same problems as before occur.

3. Shifting the instability region (surge line). This can be done with changes in the compressor design and construction, $\mathrm{e} g$, in the inlet guide vanes [34], in the vane tip clearance [9], or in the casing geometry [5], or with changes in the equipment in which the compressor discharges. This is probably more advantageous than the previous solutions.

4. Active control of rotating stall or surge by modulating the characteristics of the compression system or by modifying the inlet and/or outlet flow fields of the compressor to suppress instabilities. A compressor with active control has effectively a shifted surge line, so also the surge avoidance line can be shifted, thereby enabling the machine to operate in a region where, without active control, reliable operation was not possible or where rotating stall or surge occurred. When effective, this will make the operating region with peak performance feasible.

We propose to choose the fourth solution (active control) for further investigation and discussion. This selection does, however, not imply that the other solutions are not appropriate. In some circumstances they may be even more (cost) effective.

The motivations for selecting this topic, the third from the three measures mentioned in Section 3, instead of (one of) the two others are the following [5]

1. Surge avoidance is almost a mature field, where only incremental improvements are possible.

2. Surge detection and avoidance is hampered by the necessary speed of response, which is still an order of magnitude faster than available nowadays. The potential improvements expected are not very large.

3. Active surge control is an active area of research and promises to cause a substantial improvement, both in efficiency and in effectiveness, in the operation of turbomachines.

\section{The Control}

At this point we give a comprehensive discussion on active control. Active control can also be regarded as the effect of adding a dissipative element to the compression system, tuned to its characteristics [22], or as the process of energizing the flow field near the blade tips, where the finite rotating stall cell is likely to appear, and thus making it more disturbance tolerant [10].

For the analysis and design of control systems reliable models are beneficiary. A model able to predict surge and rotating stall for low speed axial machines has been developed and is presented in [29,21]. It is derived using some simplifying assumptions and given by PDE's and the compressor map Using Galerkin's method results in a set of integro-differential equations, and substituting a compressor map gives a set of three coupled nonlinear differential equations in pressure rise $\Psi$, mass flow $\phi$, and amplitude of the rotating stall $A$. The model describes the development of rotating stall and surge to their fully developed form, starting from infinitesimal disturbances in the flow field. It is able to predict a mix of rotating stall and surge, e.g., modified surge. According to the model both low and higher order mode instabilities occur at the same instance. This is a deficiency of the model that has been remedied, e.g., in [24] by including the effect of blade row time lags and in [38] by adding a term for momentum transfer in the compressor section due to viscous transport, both resulting in a separation of low and higher order modes. The analysis of a slightly generalized version of this model of the compression system dynamics learns that the onset of rotating stall is the effect of a pitchfork bifurcation [28]. A bifurcation analysis is also used in $[2,38,16]$. An alternative compressor model is developed in [14].

Presently, there seems no model available with the ability to predict the onset of rotating stall by finite stall cells or a blast wave, let alone a model that can describe all four of the rotating stall inception paths observed in practice (described before in Section 2) of which there could be even more than four. Control is only effective if it is possible to act on the system to be controlled and if relevant information about the system is available. A proper choice of actuators and sensors for compression systems is not obvious. For the
one-dimensional surge oscillations stabilization can be achieved with a onedimensional actuator, a valve [33], a movable wall [22], a loudspeaker [18] or a heating source, etc. A one-dimensional sensor is also sufficient, pressure and flow sensors being used presently, with flow preferred in [1]. The control leaves the steady state operating point essentially unaffected. Which types of actuators and sensors are most suitable is worth a further analysis. The one in [36] is quite exhaustive, but not very thorough, because a very simple criterion is used to detect the most promising ones. Seven actuators and five sensors that could be used for active control are indicated in Fig. 12. Some of them are considered in [36]. A close-coupled valve and a mass flow (velocity) sensor 


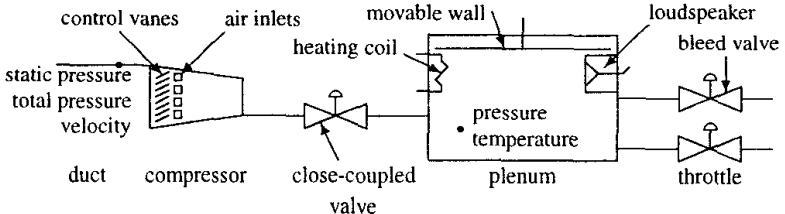

Figure 12: Compressor system with sensors and actuators

seem to be the most effective. One of the disadvantages of such a valve is the pressure loss in steady operation. A velocity sensor has the disadvantage that it may be an intrusive measurement upflow of the compressor, which should be avoided. Another possibility is to actively control the tip clearance. According to [12] a larger tip clearance shifts the surge line to lower mass flow conditions. In their results surge starts to occur at a constant mean vaned diffuser inlet flow angle. A larger clearance is, however, accompanied by a reduced efficiency.

For suppressing rotating stall one uses a two-dimensional sensor to be able to detect nonuniformness of the circumferential velocity. A common type of sensor is an array of hot-wire anemometers, perhaps in a "cross" arrangement, distributed along the circumference in front of the actuators [24]. Another one is an array of pressure sensors (microphones) [27]. To control rotating stall one-dimensional actuators are employed, see $[23,28,15,2,38]$, but it is necessary to incorporate a nonlinear (quadratic) feedback of the rotating stall amplitude in the control law. The essential features of nonlinear control with ID actuation and 2D sensing are that it does not extend the theoretical range of stability of the unstalled solution, but that it improves the dynamic behavior near the instability point (creating a larger domain of attraction, avoiding hysteresis and jump phenomena by changing the bifurcation from a subcritical to a supercritical one). This is also called an extension of the effective range of stability. It also results in a smooth transition from the unstalled to the stalled characteristic and in a possible reduction in the amplitude of the rotating stall, leading to less performance degradation. Controlling rotating stall and surge concurrently with a single actuator is also possible, as shown in [16].

To obtain an extension of the stable range of operation without stall one uses two-dimensional actuators $[32,30,24,10,20]$. At least four types of twodimensional actuators have been used for axial or mixed-flow compressors: (1) movable inlet guide vanes [30], (2) movable control vanes [24], (3) two types of distributed air inlets [10], and (4) water jets along the impeller inlet [20]. Both (2) and (3) are installed between the inlet guide vanes and the first stage of the compressor. With actuators (1), (2), and one of (3) it is possible to produce a "traveling wave" input because they can be activated individually. This requires each vane to have its own motor or each air inlet to have its own valve, a costly, complicated, and failure prone setup. The other actuators are activated as a whole, requiring only one valve and motor. The use of tip clearance control is mentioned by [10] as another possibility. For a centrifugal compressor [17] use a single eccentrically placed air inlet. [25] report on a study to define appropriate sensors/actuators for rotating stall.

[24] use a two-dimensional effector (movable control vanes) to control rotating stall in a low speed axial compressor with a few stages. Their approach is to damp the growth of linear waves, so rotating stall is not initiated. According to them the profitability of their approach to active rotating stall control is limited by the bandwidth of the actuators and by the linear and nonadaptive nature of their controller. Another limitation is raised in [6] where it is claimed that active rotating stall control for multistage high speed axial compressors is an inherently much more difficult problem than for low speed machines normally used in academic laboratory. There are no demonstrations of active rotating stall control for these machines. This is attributed to the many possible modes of instabilities, especially high amplitude blast waves, propagating from the back to the front along the compressor, that could grow into rotating stall or surge. In contrast, active control of surge (a one-dimensional phenomenon) is relatively easy for centrifugal compressors, axial fans, or low speed axial compressors with a few stages. So, graded for increasing difficulty for active control we get: surge control, rotating stall control for low speed axial machines, rotating stall control for high speed machines.

Presently, active rotating stall/surge control is mainly targeted at shifting the natural rotating stall/surge line under idealized conditions. Only limited results are known about the disturbance rejection or disturbance suppression properties, e.g. the sensitivity to flow field disturbances at the inlet of the compressor (large angle of attack) or to pressure disturbances at the outlet (combustion induced fluctuations) in aeroengines. These types of results are also necessary to be able to accurately advise on the required size of the rotating stall/surge margin that is still needed in practice.

At the moment only simple controllers are used. They normally consist of a static complex gain, only providing a real gain and a spatial and temporal phase shift. No dynamics are involved. Some exceptions are $[35,3]$, using nonlinear or adaptive control. It is expected that more advanced measurements, effectors, and controller designs will bring substantial progress.

Several points are therefore worth investigating in the quest to improve active surge control.

- The type and number of sensors used for detecting the flow conditions - The type and number of actuators used in the control of the flow $[36,25]$

- The type of controller used. Adaptive control seems to be an option [24] Also other advanced control concepts (nonlinear control, model based control) are expected to bring about improvements to, i.e., enlargement of, the feasible operating region of the compressor.

Mandatory in this work is the availability of a simple model that has a high degree of verisimilitude, and is able, at least qualitatively, to assess the effects of the proposed solutions. The model of Moore-Greitzer seems a useful starting point. Closed loop system identification may be necessary [31] to get a quantitatively more reliable representation of a specific installation. With such a model proposals for improvement can be based on a theoretical or a numerical analysis, and there is no need to rely solely on experiments.

The state of the art in compressor modeling can be summarized as follows. The detailed mechanism of surge is complex, its principal features are contained in a simple model. A model for the onset of surge phenomena is relatively simple, because it needs to describe a one-dimensional linear growth phenomenon only. Because of the stabilizing control the disturbances will not grow to their nonlinear stage, so the use of an intrinsically nonlinear model, that would be needed to describe the complete surge cycle, is not obligatory. Some modifications of the basic model, e.g. inclusion of rotor inertia [4], can improve the agreement with experimental data. The model has been applied to both axial and centrifugal compressors for the analysis and design of active surge controllers. The effectiveness of these controllers has been displayed on centrifugal and low speed axial compressors with a few stages. The control of surge in centrifugal compressors is covered extensively in the literature $[18,22,33]$.

For axial machines a model that includes both surge and rotating stall is available, see $[29,21]$. The model has been used in the control of rotating stall $[24,32]$ and rotating stall plus surge [16]. For centrifugal machines such a model has not been detected in the literature. Regrettably, only limited results for the control of rotating stall in centrifugal compressors seem to have been published [17]. On the other hand, as mentioned before, the importance of rotating stall for centrifugal compressor performance is in doubt, at least for some types of centrifugal compressors.

\section{The Consequences}

The current state of the art in compressor control has several consequences for the researcher and developer. A substantial amount of research results is already available, but not all aspects are covered yet. From the foregoing it follows that a niche topic worth investigating is the modeling, detection, and control of rotating stall in centrifugal machines. Another possibility is to check, refine, and improve previously published work. Improvement will be a tough task if it is not done by using different approaches to solve the problems. Points that are worth a further refinement are the three mentioned before (choice of sensors, actuators, and type of controller). Other specific points seem to be:

- a significant simplification of the actuation system for the control of high frequency components of rotating stall

- a check of additional aspects important for application in practice, e.g. complexity, reliability, maintainability, easy to understand by operating crew

- a check of the sensitivity for boundary distortions (i.e., inlet flow field and outlet pressure) to verify if the surge avoidance line can be shifted by the same amount (or less or more) than the surge line is shifted by active control

- an independent (on other machines) verification of the concepts used.

For the practioner, i.e., manufacturer or user, the state of the art has also several consequences. The manufacturer may incorporate active control in the machine to better satisfy customers needs. The user may then benefit from a selection of machines with a broader range of feasible operation, making the compression system simpler and cheaper.

Currently, control of rotating stall for high speed axial machines is ineffective it is not used in research laboratories, and has no practical value. Control of rotating stall's higher order harmonics in low speed machines may require complicated actuators and offers limited improvement. This approach is therefore not practical yet. It is certainly an attractive topic to be pursued in academics. Emphasis should be placed on simplifying the control system and on improving the effectiveness. For improving the effective range of stability of the unstalled solution one can employ a simple 1D actuator, so this is practical Only limited improvements can be expected because the theoretical stability range is not extended. Perhaps this approach may be applied in industrial practice at some time in the future.

The active control of surge, even for high speed machines, is a proven tech nology, requiring limited additional instrumentation and offering modest improvements in performance. It seems to be an approach that can be applied profitably in industrial practice. One thing that needs to be done is the packaging of the turbomachine and its active control system in a single unit or module. This will make the technique much more accessible and acceptable for the user. Sometimes this will be difficult to achieve. Packaging is not always possible because, at least for the surge problem, the compressor alone 
does not determine the surge characteristic and parts of the control system may need to be placed outside the compressor. When the compressor and the other parts of the system are delivered by different suppliers, which is often the case in process industry, problems may arise between the contractors. To solve this problem a cooperation between the compressor manufacturer and the other contractors is necessary. This requires at least additional coordination and supervision.

\section{The Overview}

Here, we present a tabulated overview of some relevant literature that was referred to in this paper. This overview is not supposed to be exhaustive. The goal is to give an overview that enables the reader to quickly find papers that fit with his interests. The tabulation is based on several categories in which the published literature can be divided. The categories that where deemed useful are

- the affiliation or the institution where the research was performed

- the type of treatment in the paper

- the type of turbomachine studied

- the flow instability that is taken into consideration

- a keyword for the most cormmon subjects

- a remark that highlights some specific points raised in the paper.

It is clear that Table 1 only serves as a rough categorization of the literature that could be refined further if needed.

Table 1: Overview of literature

\begin{tabular}{|c|c|c|c|c|c|c|}
\hline Paper & Affil. & Treat. & Mach. & Tnstab. & Subj. & Remark \\
\hline [1] & $\mathrm{LL}$ & AN & & SR & AS & stall and surge control \\
\hline [2] & LL & ANE & $\mathrm{AL}$ & $\mathrm{R}$ & $\mathrm{MaA}$ & bifurcations, nl control \\
\hline [3] & & & $A L$ & $s$ & A & adaptive, loudspeaker \\
\hline [4] & & $\mathrm{N}$ & & $S$ & PMa & system surge transients \\
\hline [5] & & D & C & $s$ & SA & overview of patents \\
\hline [6] & RR & A & AHM & $S$ & $\mathrm{Ma}$ & control for high-speed \\
\hline$[7]$ & & E & AHM & $\mathbf{R}$ & $\mathrm{P}$ & operation effect on stall \\
\hline [8] & & E & THM & $s$ & $s$ & working line control \\
\hline [9] & WL & E & A & $\mathbf{R}$ & $\mathrm{P}$ & onset of stall \\
\hline [10] & WL & $\overline{\mathrm{E}}$ & ALM & SR & A & control by air inlets \\
\hline [11] & WL & $\mathrm{AE}$ & ALM & SR & PMd & flow conditions \\
\hline [12] & $\mathrm{RR}$ & $\mathrm{EN}$ & $\mathrm{C}$ & S & D & matched expansion \\
\hline [13] & GTL,WL & A & $\mathrm{CA}$ & SR & A & control of flow instab. \\
\hline [14] & & AN & & SR & Md & model gas turbine engine \\
\hline [15] & LL & $\mathrm{D}$ & AM & SR & $\mathrm{P}$ & comments for video \\
\hline [16] & & NE & $\mathrm{AL}$ & SR & $\mathrm{MaA}$ & bifurcations, nl control \\
\hline [17] & WL & AEP & C & SR & A & control by air inlet \\
\hline [18] & WL & $\mathrm{E}$ & $\mathrm{C}$ & S & A & control by loudspeaker \\
\hline [19] & GE,WL,GTL & $\mathrm{AE}$ & C & $\mathbf{S}$ & PMd & wheel speed variations \\
\hline [20] & & EN & $F$ & SR & A & control by water jets \\
\hline$[21]$ & GTL & AN & AL & SR & Ma & model applications \\
\hline [22] & GTL & E & $\mathrm{C}$ & $S$ & A & movable plenum wall \\
\hline [23] & GE & $\mathrm{N}$ & A & SR & A & 1D stall control \\
\hline [24] & GTL & $\mathrm{E}$ & ALM & $\mathrm{R}$ & A & control by vanes \\
\hline [25] & GTL & AN & A & $\mathbf{R}$ & A & sensors/actuators \\
\hline [26] & PU & E & ALM & SR & $\mathrm{P}$ & unsteady response \\
\hline [27] & PU & $\mathrm{E}$ & ALM & $\mathrm{R}$ & $\mathrm{p}$ & analysis of spatial modes \\
\hline [28] & & A & $\mathrm{AL}$ & SR & $\mathrm{MaA}$ & bifurcations, nl control \\
\hline [29] & GTL & A & $\mathrm{AL}$ & SR & $\mathrm{Md}$ & stall/surge description \\
\hline [30] & GTL & E & ALS & $\mathbf{R}$ & A & control by IGV's \\
\hline [31] & GTL & $\mathrm{AE}$ & ALS & & Md & model parameters \\
\hline [32] & GTL & $\mathrm{AE}$ & A & $\mathrm{R}$ & MdA & modeling, ident., control \\
\hline [33] & GTL & E & C & S & A & control by throttle \\
\hline [34] & & $\mathrm{E}$ & $\mathrm{C}$ & $\mathrm{s}$ & D & design of IGV's \\
\hline [35] & GTL & A & & $\mathbf{S}$ & A & nl control by ccv \\
\hline [36] & GTL & A & $\mathrm{C}$ & S & A & sensors/actuators \\
\hline [37] & LL & AN & A & SR & $\mathrm{P}$ & fault detection \\
\hline [38] & & AN & $\mathrm{AL}$ & $\mathrm{R}$ & $\mathrm{MaA}$ & bifurcations, nl control \\
\hline [39] & GTL & E & C & $S$ & P & explanation of surge \\
\hline
\end{tabular}

LEGEND. Affiliation or institution - GTL: Gas Turbine Lab, WL: Whittie Lab, LL: LICCHUS, PU: Purdue University, GE: General Electric, RR: (BMW) Rolls Royce; Type of treatment - A: analytical, N: numerical, E: experimental, D: descriptive (review, etc.). P: practical; Type of machine - A: axial, C: centrifugal, F: mixed $\mathrm{fow}$, T: turbo problem - S: surge, R: rotating stall; Main subject - P: phenomena, Md: model development, Ma: model analysis, A: active control, $S$ : surge/stall avoidance, $D$ : design ABBREVIATIONS. ID: one-dimensional, IGV: inlet guide vanes, ccv: close-coupled valve, nl: nonlinear.

References

[1] O. O. Badmus, C. N. Nett, and F. J. Schork, "An integrated, full-range surge control/rotating stall avoidance compressor control system," in Proc. of the 1991 American Control Conf., vol. 3, pp. 3173-3180, IEEE, 1991.

[2] O. O. Badmus, S. Chowdhury, K. M. Eveker, C. N. Nett, and C. J. Rivera, "A simplified approach for control of rotating stall - part 1: Theoretical development, part 2: Experimental results," in Proc. 29th Joint Propulsion Conference, (Monterey, June part 2: Experimental results," in Proc. 29th Joint Propulsion Confere

[3] G. Billoud, A. Galland, C. H. Huu, and S. Candel, "Adaptive active control of [3] G. Billoud, A. Galland, C. H. Huu, and S. Candel, "Adaptive active cont

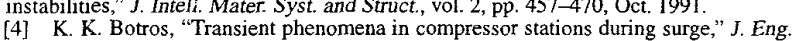
Gas Turbines and Power, vol. 116, pp. 133-142, Jan. 1994.
[5] K. K. Botros and J. F. Henderson, "Developments in centrifugal compressor surge control-a technology assessment," J. Turbomachinery; vol. 116, pp. 240-249, Apr. 1994.

[6] A. M. Cargill and C. Freeman, "High-speed compressor surge with application to active control," J. Turbomachinery, vol. 113, pp. 303-311, Apr. 1991

[7] W. W. Copenhaver and T. H. Okiishi, "Rotating stall performance and recoverability of a high-speed 10-stage axial flow compressor," J. Propulsion and Power, vol. 9, pp. 281292. Mar-Apr 1993

[8] G. J. Dadd and M. J. Porter, "Surge recovery and compressor working line control using compressor exit Mach number measurement," Proc. Inst. Mech. Eng. Part G: J. Aerosp. Eng., vol. 207, no. G1, pp. 27-35, 1993.

[9] I. J. Day, "Stall inception in axial flow compressors," J. Turbomachinery, vol. 115, pp. 1-9, Jan. 1993.

[10] I. J. Day, "Active suppression of rotating stall and surge in axial compressors," $J$. Turbomachinery, vol. 115, pp. 40-47, Jan. 1993 .

[11] I. J. Day, "Axial compressor performance during surge," J. Propulsion and Power, vol. 10, pp. 329-336, May-June 1994.

[12] G. Eisenlohr and H. Chladek, "Thermal tip clearance control for centrifugal com pressor of an APU engine," J. Turbomachinery, vol. 116, pp. 629-634, Oct. 1994.

[13] A. H. Epstein, J. E. Ffowcs Williams, and E. M. Greitzer, "Active suppression of aerodynamic instabilities in turbomachines," J. Propulsion, vol. 5, pp. 204-211, Mar.-

[14] K. M. Eveker and C. N. Nett, "Model development for active surge control/rotating stall avoidance in aircraft gas turbine engines," in Proc. of the 1991 American Control Conf., vol. 3, pp. 3166-3172, IEEE, 1991.

[15] K. M. Eveker and C. N. Nett," "Control of compression system surge and rotating stall: A laboratory-based "hands-on" introduction," in Proc. of the 1993 American Control Conf., vol. 2, (San Francisco, CA), pp. 1307-1311, IEEE, June 1993.

[16] K. M. Eveker, D. L. Gysling, and C. N. Nett, "Integrated control of rotating stall and surge in aeroengines," in Proc. 1995 SPIE Conference on Sensing, Actuation and Control in Aeropropulsion, 1995. Preprint.

[17] J. E. Ffowcs Williams, M. F. L. Harper, and D. J. Allwright, "Active stabilization of compressor instability and surge in a working engine," $J$. Turbomachinery, vol. 115 , pp. 68-75, Jan. 1993

[18] J. E. Ffowes Williams and X. Y. Huang, "Active stabilization of compressor surge," J. Fludd. Mech., vol. 204, pp. 245-262, July 1989

[19] D. A. Fink, N. A. Cumpsty, and E. M. Greitzer, "Surge dynamics in a free-spool centrifugal compressor system," J. Turbomachinery, vol. 114, pp. 321-332, Apr. 1992. [20] A. Goto, "Suppression of mixed-flow pump instability and surge by the active alteration of impeller secondary flows," $J$. Turbomachinery, vol. 116, pp. 621-628, Oct. 1994.

[21] E. M. Greitzer and F. K. Moore, "A theory of post-stall transients in axial compression systems: Part II-Application," J. Eng. Gas Turbines and Power, vol. 108, pp. 231-239, Apr. 1986.

[22] D. L. Gysling, J. Dugundji, E. M. Greitzer, and A. H. Epstein, "Dynamic control of centrifugal compressor surge using tailored structures," $J$. Turbomachinery, vol. 113 , pp. 710-722, Nov. 1991

[23] L. P. Harris and H. A. Spang III, "Compressor modeling and active control of stall/surge," in Proc. of the 1991 American Control Conf., vol. 3, pp. 2392-2397, IEEE, 1991.

[24] J. M. Haynes, G. J. Hendricks, and A. H. Epstein, "Active stabilization of rotating stall in a three-stage axial compressor," $J$. Turbomachinery, vol. 116, pp. 226-239, Apr. 1994.

[25] G. J. Hendricks and D. L. Gysling, "Theoretical study of sensor-actuator schemes for rotating stall control," J. Propulsion and Power, vol. 10, pp. 101-109, Jan.-Feb. 1994. [26] K. H. Kim and S. Fleeter, "Compressor unsteady aerodynamic response to rotating stall and surge excitations," J. Propulsion and Power, vol. 10, pp. 698-708, Sept.-Oct. 1994.

[27] P. B. Lawless, K. H. Kim, and S. Fleeter, "Characterization of abrupt rotating stall initiation in an axial flow compressor," J. Propulsion and Power, vol. 10, pp. 709-715, Sept.-Oct. 1994

[28] D.-C. Liaw and E. H. Abed, "Stability analysis and control of rotating stall," in Proc. NOLCOS'92 (M. Fliess, ed.), (Bordeaux, France), pp. 88-93, IFAC, June 1992.

[29] F. K. Moore and E. M. Greitzer, "A theory of post-stall transients in axial compression systems: Part I-Development of equations," J. Eng. Gas Turbines and Power, vol. 108, pp. 68-76, Jan. 1986.

[30] J. D. Paduano, A. H. Epstein, L. Valavani, J. P. Longley, E. M. Greitzer, and G. R. Guenette, "Active control of rotating stall in a low-speed axial compressor," $J$. Turbomachinery, vol. 115, pp. 48-56, Jan. 1993.

[31] J. Paduano, L. Valavani, and A. H. Epstein, "Parameter identification of compressor dynamics during closed-loop operation," J. Dynamic Systems, Measurement, and 703, Dec. 1993

[32] J. D. Paduano, L. Valavani, A. H. Epstein, E. M. Greitzer, and G. R. Guenette, "Modeling for control of rotating stall," Automatica-J. IFAC, vol. 30, pp. 1357-1373,

[33] J. E. Pinsley, G. R. Guenette, A. H. Epstein, and E. M. Greitzer, "Active stabilization of centrifugal compressor surge," $J$. Turbomachinery, vol. 113, pp. 723-732, Nov. 1991. [34] C. Rodgers, "Centrifugal compressor inlet guide vanes for increased surge margin," J. Turbomachinery, vol. 113, pp. 696-702, Nov. 1991.

[35] J. S. Simon and L. Valavani, "A Lyapunov based nonlinear control scheme for stabilizing a basic compression system using a close-coupled control valve," in Proc. of the 1991 American Control Conf., vol. 3, pp. 2398-2406, IEEE, 1991.

[36] J. S. Simon, L. Valavani, A. H. Epstein, and E. M. Greitzer, "Evaluation of approaches to active compressor surge stabilization," $J$. Turbomachinery, vol. 115, pp. 57 67, Jan. 1993.

[37] G. Vachtsevanos, H. Kang, J. Cheng, and I. Kim, "Detection and identification of axial flow compressor instabilities," J. Guidance, Control, and Dynamics, vol. 15, pp. 1216-1223, Sept.-Oct. 1992

[38] H. O. Wang, R. A. Adomaitis, and E. H. Abed, "Nonlinear analysis and control of rotating stall in axial flow compressors." in Proc. of the 1994 American Control Conf vol. 2, (Baltimore, Maryland), pp. 2317-2321, IEEE, 1994.

yol, 2, (Baltimore, Maryland), pp. 2317-2321, IEEE, 1994.
[39] A. M. Wo and J. P. Bons, "Flow physics leading to system instability in a centrifugal pump," $J$. Turbomachinery, vol. 116, pp. 612-620, Oct. 1994. 